\title{
Erratum to: Detection and Neutralization of Unsymmetrical Dimethylhydrazine on the Surface of Construction Materials
}

\author{
K. E. Polunin ${ }^{a}$, A. V. Ul'yanov ${ }^{a}$, I. A. Polunina ${ }^{a}$, and A. K. Buryak ${ }^{a, *}$ \\ ${ }^{a}$ Frumkin Institute of Physical Chemistry and Electrochemistry, Russian Academy of Sciences, Moscow, 119071 Russia \\ *e-mail: akburyak@mail.ru
}

Received June 16, 2021; revised June 16, 2021; accepted June 16, 2021

DOI: $10.1134 / \mathrm{S} 0036024421310010$

The article "Detection and Neutralization of Unsymmetrical Dimethylhydrazine on the Surface of Construction Materials," written by K. E. Polunin, A. V. Ul'yanov, I. A. Polunina, and A. K. Buryak, was originally published electronically in Springer-Link on 5 April 2021 without Open Access. After publication in volume 95 , issue 3 , pages $530-537$ the authors decided to make the article an Open Access publication. Therefore, the copyright of the article has been changed to (C) The Author(s), 2021 and the article is forthwith distributed under the terms of a Creative
Commons Attribution 4.0 International License (http://creativecommons.org/licenses/by/4.0/, CC BY), which permits use, duplication, adaptation, distribution and reproduction of a work in any medium or format, as long as you cite the original author(s) and publication source, provide a link to the Creative Commons license, and indicate if changes were made.

The original article can be found online at https://doi.org/10.1134/S003602442103016X 